\title{
Vestuario de cine: el relator silencioso
}

Solana Roffe*

Resumen: Cuatro ejes de modificaciones corporales a través de la moda: lujo/pertenencia social, femineidad/maternidad, poder/masculinidad y objeto de deseo/castidad.

La idea es un recorrido histórico y cultural de cómo a través de la moda el cuerpo femenino es modificado de su estructura original a través de la ropa interior o estructuras internas de la ropa, para denotar alguno de esos cuatro aspectos según los preceptos culturales de cada epoca y cultura analizada.

Palabras clave: cine - deseo - lujo - pertenencia - relator - silencioso - social.

[Resúmenes en inglés y portugués en la página 86]

${ }^{(*)}$ Diseño de vestuario teatral, diseño y desarrollo de colecciones para mujer, novias, teens, bebés y niños. Consultora, ambientadora, productora y estilista de moda, especializada en indumentaria y corsetería de época. Asesora de imagen y personal shopper. Docente de diseño, moldería, ilustración de moda a mano y digital, proyectual, historia del traje, fichas técnicas, técnicas de producción y armado de colección.

En la película Titanic (dir. James Cameron 1997) el rol femenino principal, Rose DeWitt Bukater, una joven de la aristocracia inglesa que al comenzar el film se ajusta perfectamente a lo que se espera de ella, muestra muy claramente cómo el mensaje sutil del vestuario relata en paralelo al guión la metamorfosis del personaje.

Al principio del film, cuando se nos presenta el personaje, la vemos descender de un auto de lujo con un traje blanco y violeta y un sombrero de ala anchísima. Si analizamos la simbología del color y la morfología del traje veremos que acompaña la actitud aristocrática, rígida y contenida que posee el personaje en un principio. El blanco simboliza luz, bondad, inocencia, pureza, virginidad, optimismo, perfección, aislamiento y frialdad. El violeta simboliza sabiduría, creatividad, independencia, dignidad, serenidad, cambio, transgresión. El blanco nos dice en este caso que el personaje es distante y frío; a la vez puro e inocente en muchos aspectos. El violeta es también símbolo de transformación, siendo éste uno de los ejes principales de la historia: el cambio de actitud del personaje al dejar su mundo lleno de rigidez y protocolo social para explorar sus emociones y su libertad. 
Sin embargo, no es solo el color en este traje el que nos dice cómo es el personaje y la mutación que transitará: la silueta y la morfología también aportan códigos sutiles. El traje posee líneas rectas en el tejido y formas agudas en las solapas y la chaqueta, pero la falda a pesar de ser "trabada", tipología de la época que impedía dar pasos largos o moverse con libertad, acorde al rol social femenino de la Belle Époque, tiene líneas redondeadas (las cuales asociamos con falta de rigidez) justamente en la zona de las piernas, quizás adelantándonos que el personaje en algún momento saldrá del "traje jaula”. El lugar donde se eligió ubicar las líneas rectas y las redondeadas porta otro mensaje: líneas rectas en la parte superior del cuerpo, que asociamos al ser espiritual, preponderancia del violeta en las solapas, justo sobre el corazón, y más proporción de blanco y redondez en la parte inferior del cuerpo, asociada al movimiento, la sexualidad y la libertad.

El sombrero, que también responde con exactitud a la moda de la época resulta casi una "carga" sobre la cabeza del personaje por el tamaño y la desproporción, tal como los mandatos sociales, de género y familiares. Todo el conjunto es de frialdad y rigidez, de aristocracia casi rancia, de pesados códigos sociales, pero nos deja indicios muy sutiles de que este personaje en algún lugar no responde a ese estereotipo.

En otra de las escenas, el personaje de Rose se encuentra en la cena formal de primera clase, usando un traje de tul negro bordado con cuentas sobre un forro de color rojo vibrante. En medio de la cena el personaje se ve desbordado por la carga de la vida que le espera al casarse con la persona elegida por su madre para ella. Sabe que le espera una vida vacía, de costumbres rígidas y figuración sin ningún lugar para sus deseos personales ni libertad, donde deberá desempeñar el papel de dama de sociedad acorde a las normas imperantes. En ese momento sale corriendo a la cubierta del barco para saltar por la borda y escapar a ese destino; y aquí es donde el traje nos brinda una información subliminal que esta vez sí coincide con lo que la actriz construye desde lo corporal y gestual: se encuentra desbordada, las emociones a flor de piel, hay ira e irracionalidad, peligro y posibilidad de muerte. La paleta de color del traje refuerza el valor simbólico del mensaje: el rojo representa: sangre, fuego, calor, revolución, alegría, acción, pasión, fuerza, disputa, desconfianza, destrucción e impulso, así mismo crueldad y rabia. El negro simboliza: poder, elegancia, seriedad, muerte, misterio y lo desconocido; también simboliza el dolor y la pena. Este relato cromático es acompañado por las texturas del traje, el tul negro que simboliza entre otras cosas la elegancia de su clase social es donde se encuentra el recurso del bordado de azabaches, y la forrería color roja, que representa la parte emocional es de seda sin ornamentación, representando el ser emocional y sensible, que se encuentra debajo del caparazón social de riqueza del tul negro bordado.

$\mathrm{Al}$ avanzar el relato de la historia, vemos que los dos personajes principales se encuentran en la cubierta de primera clase y pasean mientras se conocen. El diálogo transita las diferencias de clase entre ambos, las diferencias en sus vidas, anhelos y expectativas para el futuro, y Jack empieza a desarmar de a poco ese caparazón que posee el personaje de Rose en un principio. El traje de Rose en esta escena es blanco y amarillo, un traje de día sencillo pero que nos aporta una vez más un discurso mucho más rico que el del diálogo entre ambos personajes. 
El amarillo es un color brillante, alegre, que simboliza el lujo, el sol y el calor del día. Se asocia con la parte intelectual de la mente y la expresión de nuestros pensamientos. Es por lo tanto, el poder de discernir y discriminar, la memoria y las ideas claras, el poder de decisión y capacidad de juzgarlo todo. También ayuda a asimilar las ideas innovadoras y aporta la habilidad de ver y comprender los diferentes puntos de vista. Si recordamos entonces, que el diálogo gira en torno a las diferencias de clase, la incorporación de conceptos nuevos que le brinda el personaje de Jack, así como la comprensión de su modo de vida y sus experiencias, se produce un intercambio entre los dos personajes y una vez más como hemos visto el color amarillo simboliza todos estos conceptos. Toda la escena se desarrolla a la luz del sol, hay mucha claridad reforzada por el simbolismo del color amarillo (que contrasta con la oscuridad y la muerte próxima de la noche anterior donde Rose intenta saltar del barco).

En otra de las escenas, durante la cena en primera clase con todos los personajes de la aristocracia, Rose viste un traje similar al de la escena en la que casi salta por la borda, pero con algunas diferencias muy sutiles que nos cuentan de su afecto creciente por Jack. El traje de cena es de gasa transparente negra bordada con cristales sobre un forro de color. Analicemos el recurso de vestuario de acuerdo a las circunstancias: Rose sigue siendo un personaje que todavía no se ha liberado de los mandatos sociales (sobrevestido de gasa negra bordada con cristales) pero lo que sucede por debajo de ese exterior socialmente correcto está representado por la forrería esta vez de color rosado. El rosado simboliza sensualidad refinada, sensibilidad del alma, sentimiento de felicidad, devoción, amor platónico, emotividad, sueños. En este punto de la historia se revelan los sentimientos de Rose hacia Jack un poco escondidos por la cáscara social que todavía la recubre. Es además el momento en el cual se escapa hacia tercera clase y se libera un poco de sus restricciones (esto se muestra claramente cuando baila y recoge la falda dejando ver mucho más del color rosado de la forrería). Otro detalle del relato muy ligado al vestuario en esta escena, es cuando Rose se quita el calzado para bailar con Jack más cómodamente en tercera clase: la simbología de "liberar" los pies, que son nada más y nada menos que los que nos llevan por diferentes caminos en la vida, muestra la mutación que el personaje va transitando y el despojo de mandatos que va sufriendo a lo largo de la historia.

Una de las escenas más emblemáticas del film es cuando Rose se está vistiendo ayudada por la mucama. Su madre entra en la habitación y le prohíbe seguir viendo a Jack, le explica que debe ceñirse a cumplir su compromiso con el personaje de Cal (a quien ella no ama) para sacar a la familia de la pobreza, de alguna manera, la vuelve a encerrar dentro del protocolo social, la corrige y restringe. No es casualidad entonces que esta conversación se lleve a cabo mientras su madre le ciñe el corset hasta lo imposible, ahogándola, atándola. Por otra parte la paleta de color del vestuario de Rose en ese escena es el blanco, que entre otras cosas simboliza la fragilidad: Rose está indefensa frente a la agresividad materna en el mandato, ella se encuentra expuesta (está en ropa interior) y su madre está completamente vestida, hay una asimetría de fuerzas, una lucha entre el status quo y la rebeldía.

Los personajes masculinos también conllevan mensajes sutiles en el vestuario: Más allá de la reconstrucción histórica, el personaje de Jack, siempre está vestido, salvo en una excepción que analizaremos más adelante, con colores neutros y amarronados. El simbolismo 
del color marrón nos habla de estabilidad, laboriosidad, humildad y sencillez, asociado también con cualidades masculinas. Todos estos tonos son los que encontramos en el vestuario del personaje de Jack en concordancia con sus cualidades.

En la única ocasión en la que lo vemos vestido de otra manera es en el momento en que "asciende" a primera clase como invitado en agradecimiento por haber salvado a Rose. En dicha escena se encuentra vestido con el traje (prestado por Molly Brown) formal, de etiqueta, correspondiente al uso de la época; que también portan los demás pasajeros de esa clase. Lo interesante es analizar cómo tanto en el contexto social y en el emocional inherente al personaje el traje lo transmuta transitoriamente: el "ser" en base al vestuario, la "máscara" que debe llevar para ser aceptado y mezclarse con la alta burguesía en la cubierta de primera clase. Sin embargo, así como el traje es prestado, la mutación del personaje es transitoria: es un traje que no le pertenece, es una "máscara" de alguien más que toma prestada por un rato para un fin determinado, al final de la noche vuelve a habitar el traje que le pertenece. Del mismo modo, Rose, después de descalzarse y liberarse de los mandatos sociales, bailando y levantando el vestido "opresor" vuelve a su "máscara" de primera clase con sus códigos y preceptos anteriores a conocer a Jack.

Como último ejemplo de la transformación del personaje de Rose, cuando ha decidido dejar atrás su vida aristocrática para huir con Jack viste un traje completamente distinto a los que había usado hasta entonces. Este traje consiste en un vestido suelto y volátil, en colores claros, confeccionado en gasa. Todo el mensaje es de soltura, libertad y liviandad: como si el personaje de Rose se hubiese liberado finalmente de las ataduras y la rigidez que le imponía su condición social y su género. Esta imagen se vuelve más poderosa al resaltar la volatilidad del vestido porque el personaje corre por el barco haciendo flotar la tela alrededor y se suelta el cabello; los colores pasteles resaltan el lado infantil y lúdico de la situación, ya que los personajes corren y se esconden otro que los persigue, burlándose de él y disfrutando del juego. Los colores pastel del vestido refuerzan el carácter aniñado del juego y el lado divertido del personaje, que en la escena descripta al principio se nos presenta formal, rígido y totalmente serio.

Otro personaje que nos muestra con su vestuario un discurso paralelo al libreto es la madre de Rose. En la mayoría de las escenas está vestida de negro, al igual el personaje de Cal (con quien Rose se casará por conveniencia).

En la escena descripta anteriormente donde la madre de Rose ciñe el corset mientras le explica que las mujeres deben sacrificarse y casarse por conveniencia, aunque no sea justo, es en la escena donde más sentido cobra el vestuario negro de este personaje ya que el negro se asocia con el silencio, el infinito y la fuerza pasiva femenina y misteriosa. Esa es la enseñanza que le transmite a su hija, el poder pasivo femenino, y también la resignación esperada de acuerdo a su género y rol social.

El personaje de Cal, es violento, misógino, traicionero y egoísta y en todo momento lo vemos con vestuario negro simbolizando el mal en contraposición al blanco de Rose y el sencillo marrón de Jack. Aquí es donde se nos revela la naturaleza definitiva de los personajes: en la escena del hundimiento, aunque los de Jack y Cal no transmutan a lo largo de la historia. El vestuario negro de Cal, entonces nos muestra, resaltado por tipologías sastreras que subrayan las líneas rectas, el poder, la elegancia, la formalidad, la muerte. El 
negro también simboliza autoridad, fortaleza, intransigencia: algunas de las características del personaje malvado de la historia.

Otro film que nos brinda muchísima información visual desde el diseño de vestuario (realizado por Eiko Ishioka) es la película Drácula, escrita por Bram Stoker en 1897 y dirigida por Francis Ford Coppola en 1992. En este caso el vestuario nos dará la pauta de la relación entre los personajes de la historia, vinculándolos a lo largo del film con recursos de diseño en sus respectivos vestuarios.

El personaje de Elisabeta, creyendo que su amado ha muerto a manos de los turcos, se suicida y da comienzo a la leyenda de Drácula, que renegando de Cristo por la pérdida de su amada se transforma en el vampiro que da vida a la historia. Elizabeta reencarnará siglos más tarde en Mina Harker, a quién el conde Drácula ha buscado durante todo este tiempo y de quien se enamorará una vez más. El vínculo entre los personajes de Mina y Elizabeta es reforzado por el vestuario constantemente. La primera porta un vestuario renacentista y la segunda victoriano, pero aún así la diseñadora logró vincularlos con signos sutiles de conexión. En las escenas iniciales cuando vemos a Elizabeta vestida con un traje renacentista en color verde intenso, éste tiene un emblema bordado con un ave bicéfala y varias hojas doradas. Durante toda la película Mina vestirá trajes que poseen las mismas hojas del bordado del traje renacentista: a veces en un labrado, otras, bordado, pero las hojas están presentes para vincularlas, así como la paleta de color. El personaje de Elizabeta es pasional y posee cierto descontrol y opulencia, mientras que Mina responde a los estándares de género de la época victoriana, es recatada, tiene cierta inocencia y timidez, por lo que la paleta de color es en verdes mucho más claros. Podemos decir entonces, que Mina es una versión algo desdibujada de Elizabeta en un principio, luego lentamente se enamorará de Drácula y mutará su vestuario hacia el negro con interiores del mismo verde del personaje del principio, como si hubiera recordado su vida anterior (y la conservara en su interior) y se hubiese cubierto definitivamente de "oscuridad".

En el traje victoriano de Drácula también veremos las hojas que vinculan a los dos personajes, en este caso bordadas en una chaqueta de estilo militar. Este elemento tan simple sirve de nexo a través del tiempo para estos dos amantes que se reencuentran y están atados el uno al otro más allá de la conciencia, el tiempo y la voluntad.

En el principio del film vemos al personaje de Drácula vestido con su armadura, un diseño cuya morfología semeja la musculatura humana (además es de color rojo) y el casco posee terminaciones puntiagudas, semejando cuernos (la leyenda popular Rumana consideraba al Vlad Tepes, el verdadero conde Drácula, un demonio). Cuando Drácula encuentra a Elizabeta muerta se desgarra de dolor; la armadura roja, con nervaduras y bloques musculares marcados le dan a la escena el tono descarnado, de furia y sufrimiento que transita el personaje. El color rojo, como hemos visto antes, nos recuerda al amor, la pasión y la sangre: tres temas alrededor de los cuales gira el film. Este color se encuentra presente en varias escenas en el vestuario de Drácula que usa una bata con cola larguísima (como arrastrando siglos de sangre sobre sus espaldas) con el mismo emblema descripto en el traje de Elizabeta; una vez más el recurso textil los conecta. Hay una escena en particular en la cual Mina se enamora definitivamente de Drácula y en ella, lleva un traje rojo con metros de tela plegada en la cola del vestido, recordando la bata mencionada más arriba. La elección del color 
como hemos dicho en esta escena tiene que ver con la pasión a la que se entrega, lejos del personaje tímido algo deslucido de Mina con los verdes pálidos y los cuellos cerrados del principio. Otro recurso curioso es el tratamiento que se le da en la comunicación al cabello: a medida que va enamorándose de Drácula y entregándose a él va soltándolo hasta tenerlo totalmente libre. Como vimos en el ejemplo de Titanic el cabello femenino porta una innegable simbología de libertad y sexualidad, de alguna manera muestra el soltarse de las ataduras, propias o impuestas desde el exterior (no en vano en la edad media el cabello debía ocultarse con velos y sombreros lo más posible).

Otro de los personajes de la historia es la amiga de Mina, Lucy, que desde un principio a pesar de coexistir con Mina en la época victoriana, siempre está vestida con reminiscencias renacentistas. Sus trajes y su cabello no corresponden históricamente a la época en la que se desarrolla la historia, pero este vestuario nos ayuda a comprender el carácter hedonista de Lucy, mucho más centrado en el placer que Mina (el renacimiento fue una época más centrada en el placer que la vitoriana, caracterizada por la represión sexual y la rigidez moral). Lucy es el primer personaje femenino que Drácula transforma en vampiro y a través del vestuario vemos cómo varía la paleta de color al rojo y a tipologías que dejan el cuerpo expuesto, alejándose de la reconstrucción de época literal, pero reforzando el concepto sexual de la transformación del personaje. El vestuario que vemos en Lucy cuando es seducida por Drácula además de ser rojo, con todas las connotaciones que hemos descripto para este color, tiene una modificación en el textil que genera líneas horizontales, como si el traje la aprisionara, una especie de cárcel justo cuando es "atrapada" por la oscuridad. Como remate del personaje, Lucy al transformarse en vampiro, sale de su tumba para alimentarse de sangre y en esa escena vemos un traje completamente renacentista, nupcial, totalmente blanco, con una enorme gorguera y cola (inspirado en el retrato del siglo XVI Margareth Bromsen, de autor desconocido) que destaca aún más las manchas de sangre y la palidez del maquillaje. El uso del blanco en una escena de terror aún cuando siempre se ha asociado al negro a lo maligno, genera un efecto mucho más poderoso y tenebroso El personaje de Van Helsing tiene un costado ambiguo. La novela fue escrita a fines del siglo XIX, volcando todo el pensamiento de la época en cuanto a la ciencia y la religión. Es un momento de transición donde lo científico comienza lentamente a tener preponderancia sobre la superstición, por eso el `personaje que finalmente vence a Drácula (un personaje ligado a lo mítico: el demonio y la renuncia a Cristo en el principio del film) es un hombre de ciencia. Lo curioso es que a pesar de eso, el vestuario tiene resabios religiosos, por momentos parece el hábito de un cura y por momentos un médico victoriano. En las escenas finales del film Drácula aparece vestido con una túnica dorada (inspirada en los cuadros de Gustav Klimt) casi bizantina, en una actitud que recuerda a Jesuscristo, nos recuerda un ángel caído, nos hace amarlo en vez de temerle, y comprender que lo que lo llevó a ser esa criatura oscura fue el amor a Elizabeta. El vestuario no ha hecho aquí más que reforzar el concepto del film: no es una historia de horror, es una historia de amor, de pasión y de erotismo con toques de terror.

La diseñadora Eiko Ishioka también realizó el vestuario de la película Mirror, mirror (2012) dirigida por Tarsem Singh. El film es la adaptación del cuento de los hermanos Grimm Blancanieves y el vestuario utiliza todos los recursos estéticos del cuento de hadas, mezclando el barroco, el kitch, el mundo animal y vegetal. 
Mientras que el vestido de Blancanieves cuenta con hojas entrelazadas y enredaderas que predicen su exilio en el bosque. En toda la película se traza una conexión con las aves: el traje de Blancanieves para el baile al que tiene prohibido asistir, es un cisne, resaltando la pureza del personaje y su inocencia.

La reina se muestra con cuellos de encaje que nos recuerdan las espaldas de los reptiles resaltando su naturaleza traicionera. Este exceso en su vestuario responde a su ambición por el lujo y la frivolidad, sus trajes son siempre opulentos y exagerados.

Los trajes de la corte son sublimes. En la fiesta de casamiento de la reina, se los ve ridículamente vestidos con colores saturados, pelucas y maquillajes teatrales. Toda la película tiene referencias a la relación interior exterior de las prendas reforzando el carácter lúdico de algunos personajes y el tono fantasioso de la historia.

Un ejemplo acerca del lenguaje de nuestro relator silencioso es la película Moulin Rouge (2001), dirigida por Baz Luhrman - vestuario Katherine Martin. La historia está basada en La dama de las Camelias de Alejandro Dumas y La Traviata de Giussepe Verdi.

Los personajes principales son Christian, un joven inglés, bohemio y romántico que busca entre otras cosas el amor verdadero y Satine, una prostituta aspirante a actriz del Moulin Rouge. El personaje de Christian, así como el de Jack en Titanic: se transforma al habitar el traje de otra clase social, en este caso del duque (personaje obsesionado con tener a Satine solo para él), con quien lo confunden y así logra llegar a Satine, quien de otro modo jamás lo hubiese recibido. En la escena en la que cantan Satine y Christian, ella viste de rojo, acompañando el sentimiento del personaje, que termina enamorándose de Christian a pesar de su pobreza. En cambio, cuando se ve obligada a visitar al duque para cumplir la promesa de Ziedler, viste de color azul noche denotando frialdad y vacío, en contraposición al rojo pasional que vestía con Christian. En esta escena es preponderante el rol del accesorio que lleva: un collar espectacular de brillantes, pero que de alguna forma la ahoga y la aprisiona igual que el duque.

Hay otra escena en la cual Satine debe terminar con Christian y su vestuario se torna gris y deslucido. El gris es el color de la evasión, independientemente que sea un gris claro o un gris oscuro. Esto se relaciona con separarse de todo, permanecer al margen de todo, y huir de compromisos, de frialdad y un poco de muerte al estar compuesto de negro. El gris como en la naturaleza nos presagia densas y oscuras nubes grises, la niebla y el humo exactamente como sucederá en la historia a partir de ese momento.

El personaje de Ziedler siempre está vestido a semejanza de los domadores de circo, es el presentador del Moulin Rouge, el que decide los destinos y explota a los personajes que allí habitan. El atuendo subraya el carácter circense del lugar: es un lugar de exhibición, de criaturas extrañas, de diversión y de excesos, pero que detrás del telón muestra una cara mucho más oscura y triste. El contraste del colorido del vestuario en escena y lo que sucede detrás muestra muy bien esta paradoja. Por otro lado el vestuario responde a la estética de videoclip del director mezclando estilos de distintas épocas reforzando el concepto de circo. Podemos concluir este análisis diciendo que el vestuario es tan protagonista como el actor, tan expresivo como el gesto y la palabra, y tan sutil como las emociones que transmite y la historia subyacente que nos cuenta. El trabajo del diseñador de vestuario no es aislado, por el contrario construye con el actor y el director un discurso completo y un sistema de signos que envuelve al espectador y lo incluye en la historia, haciéndolo comprender al personaje y sus circunstancias mucho mejor, aún casi sin darse cuenta. 


\section{Referencias Bibliográficas}

Cameron, J. (director). (1997). Titanic [película]. 20th Century Fox.

Coppola, F. F. (director). (1992). Drácula, [película]. Columbia Pictures.

Francés, R. (1985). Psicología del Arte y de la Estética. Madrid: Akal.

Ishioka, E. (2006). Eiko. Page One Publishing.

Kowzan,T. (1997). El signo en el teatro. Madrid: Editorial Arco.

Laver, J. (1992). Breve Historia del traje y la Moda. Madrid: Editorial Cátedra.

Luhrman, B. (diriector). (2001). Moulin Rouge [película]. 20th Century Fox.

Muñoz, F. (Junio 6, 2010). artesescénicas.wordpress.com.

Sansz, J. C. (2003). El libro del Color. Madrid: Alianza.

Summary: Four axis of body transformation through fashion: luxury-social belonging, feminity-motherhood, power-masculinity and object of desire-chastity. We propose an historical and cultural journey through fashion to see how women body is structurally modified through underwear or clothes internal structure to denote any of these four aspects as cultural precepts of every age and culture analyzed.

Keywords: belonging - cinema - desire - luxury - narrator - silent - social.

Resumo: $\mathrm{O}$ artigo consiste em um recorrido histórico e cultural sobre como através da moda o corpo feminino se modifica de sua estrutura original através da roupa interior ou estruturas internas da roupa, para denotar, segundo os preceitos culturais de cada época e cultura analisada, alguns destes quatro eixos: luxo/pertença social; feminilidade/maternidade; poder/masculinidade e desejo/castidade.

Palavras chave: cinema - desejo - luxo - pertença - relator - silencioso - social. 